\title{
Development of Mathematical Model to Predict the Co-Efficient Of Performance in A Refrigeration System Working with R404a
}

\author{
SP.Arunkumar,C.Prabha, M.Anwarullah
}

\begin{abstract}
This paper exhibits an orderly way to deal with build up the numerical model for anticipating the coefficient of execution of $R 404 a$ which is an eco benevolent refrigerant and broadly utilized in refrigeration and airconditioning ventures. The procedure parameters are loop width, curl pitch and loop length. Reaction surface procedure (RSM) is utilized to build up the scientific model.Analysis of Variance (ANOVA) system is utilized to check the ampleness of the created model. The created numerical model can be utilized adequately at 95\% certainty level. The coefficient of execution of $R 404 a$ in a fume pressure refrigeration framework has been examined in detail.
\end{abstract}

Keywords- ANOVA, Vapor Compression Refrigeration, R404a, Coil dia, Coil Pitch, Capillary Tube.

\section{PRESENTATION}

In little refrigeration and cooling frameworks, one of the generally utilized extension gadgets to control the stream pace of refrigerants is the slim cylinder. Slender tube is a container of hardly any millimeter inner distance across, generally extending between $0.5 \mathrm{~mm}$ to $2 \mathrm{~mm}$. Despite the fact that the gadget needs dynamic capacity (Mechanical or Electrical) to effectively acclimate to any abrupt change in the heap conditions, it is still being used due to its effortlessness, minimal effort and prerequisite of low blower beginning torque [1]

Akintude [4] had likewise researched the impacts of different geometries of slim cylinders dependent on the loop width and lengths alone, with no specific consideration put on the impact of curl pitch. He inspected the impacts of pitch of both helical and serpentine snaked hairlike cylinder on the exhibition of a fume pressure refrigeration framework. A few slender containers of equivalent length $(2.03 \mathrm{~m})$ and fluctuating pitches, snaked widths and serpentine statures were utilized. Both channel and outlet weight and temperature of the test segment (hairlike tube) were estimated and used to appraise the COP of the framework.

Melo et al. [5] talked about the impact of slim length, hairlike measurement, refrigerant subcooling, consolidating

Revised Manuscript Received on September 14, 2019.

SP.Arunkumar, Professor, Department of Mechanical Engineering, Siddhartha Institute of Technology and Sciences, Narapally,Telangana 501301, India.

C.Prabha Assistant Professor, School of Mechanical Engineering, Karunya University, Coimbatore,Tamilnadu - 641 114, India.

Dr.M.Anwarullah, Professor, Department of Mechanical Engineering, Siddhartha Institute of Technology and Sciences, Narapally,Telangana 501301, India. weight and kind of refrigerant on the mass stream rates through the vessels. The tests were performed with three refrigerants, for example, R12, R134a and R600a and at various gathering weights and levels of subcooling under gagged stream conditions. Eight vessels with various blends of lengths, measurements and cylinder harshness were utilized, and broad information were gathered. An ordinary, dimensional investigation was performed to infer connections to anticipate the mass stream rates for various refrigerants.

The created models are tried for their ampleness and exactness utilizing ANOVA and affirmation tests, separately.

\section{TEST WORK}

The test arrangement comprises of an evaporator, a hermitically fixed responding blower, air cooled condenser, channel, beneficiary tank, rotometer, ball valve with manual control, helical curl slender cylinder with shifted inward slim cylinder distances across, advanced vitality meter and Wattmeter

At first the framework was flushed with nitrogen before charging the refrigerant. This was done to expel the polluting influences and the dampness from the framework Presently the refrigerant R404a is surged into the framework. The framework achieved consistent state condition following a run of three hours and perceptions were made.

The internal width of the hairlike cylinder is fluctuated as $0.66 \mathrm{~mm}, 0.78 \mathrm{~mm}, 0.96 \mathrm{~mm}, 1.07 \mathrm{~mm}$ and $1.2 \mathrm{~mm}$, and the curl distance across was differed as $80 \mathrm{~mm}, 120 \mathrm{~mm}, 160$ $\mathrm{mm}, 200 \mathrm{~mm}$ and $240 \mathrm{~mm}$. The pitch was fluctuated by 8 $\mathrm{mm}, 10 \mathrm{~mm}, 12 \mathrm{~mm}, 14 \mathrm{~mm}$ and $16 \mathrm{~mm}$.

\section{PLAN OF EXAMINATION}

The exploration work was wanted to be done in the accompanying advances:

1. Identifying the significant procedure parameter

2. Finding the upper and lower points of confinement of the procedure parameter Viz. Loop diameter(D),

Inward distance across of the narrow (d) and curl pitch (P).

3. Development of structure matrix

4. Conducting the investigations according to the plan 
lattice.

5. Recording the reactions, viz Coefficient of execution.

6. Development of the scientific model.

7. Checking the ampleness of the models created.

8. Conducting the congruity trials and looking at the outcomes.

9. Presenting the impacts of the procedure parameters onCoefficient of execution in graphical structure and breaking down the outcomes.

\subsection{Identifying the significant procedure parameter}

In view of starter preliminaries, the free procedure parameters influencing the mechanical properties were recognized as loop diameter(D),inner distance across of the slender $(d)$ and curl pitch $(P)$

Table 1. Process parameter and its levels

\begin{tabular}{|c|c|c|c|c|c|c|c|}
\hline \multirow{2}{*}{ Parameters } & \multirow{2}{*}{ Units } & \multirow{2}{*}{ Notations } & \multicolumn{5}{|l|}{ levels } \\
\hline & & & -1.682 & -1 & 0 & 1 & 1.682 \\
\hline Coil Diameter & $\mathrm{D}$ & $(\mathrm{mm})$ & 80 & 120 & 160 & 200 & 240 \\
\hline Coil Pitch & $\mathrm{P}$ & $(\mathrm{mm})$ & 8 & 10 & 12 & 14 & 16 \\
\hline $\begin{array}{l}\text { Internal } \\
\text { Diameter of the } \\
\text { capillary }\end{array}$ & $\mathrm{d}$ & $(\mathrm{mm})$ & 0.66 & 0.78 & 0.96 & 1.07 & 1.2 \\
\hline
\end{tabular}

\subsection{Development of Design Matrix}

framework chose configuration will be appeared in Table 2. It is a three-level elements played five focal composite structure comprising of 20 sets condition code comprises of a full factorial $23=8$, in addition to 6 points and 6 star focus focuses to 20 trial runs permitted estimation of the impact intuitive direct, quadratic and two-way process parameters on the mechanical properties.

\subsection{Testing comparing structure network}

Tests were completed in agreement framework plan in fume pressure refrigeration frameworks utilizing R404a as refrigerant. Slim pipe width (D) inside the fine distance across (d) and the pitch of the hairlike cylinder (P) which differs an evaporator temperature was kept up at $-5^{\circ} \mathrm{C}$ and

\subsection{Finding the points of confinement of control variable}

Preliminary runs are directed to locate the upper and lower point of confinement of procedure parameters, by changing one of the parameter and keeping the remainder of them at steady esteem. The furthest reaches of a factor was coded as $=1.682$ and as far as possible as -1.682 . The moderate coded valuesbeing determined from the accompanying relationship.

$\mathrm{Xi}=1.682[2 \mathrm{X}-(\mathrm{Xmax}+\mathrm{Xmin})] /(\mathrm{Xmax}-\mathrm{Xmin})(1)$

Where $\mathrm{Xi}$ is the required coded value of a variable $\mathrm{X}$; and $\mathrm{Xis}$ any value of the variable from Xmin to Xmax, Xmin is the lowerlimit of the variable and Xmax is the upper limit of the variable[18]. The selected process parameters with their limits, units andnotations are given in Table 1.

Table 2.Design matrix and experimental value with predicted value of coefficient of performance

\begin{tabular}{|l|l|l|l|l|l|}
\hline \multirow{2}{*}{ Trail no } & \multicolumn{2}{l}{$\begin{array}{l}\text { Design matrix } \\
\text { process parameter }\end{array}$} & \multicolumn{2}{l}{ Coefficient of performance } \\
\cline { 2 - 6 } & $\mathrm{D}$ & $\mathrm{P}$ & $\mathrm{L}$ & Experimental value & Predicted value \\
\hline 1 & -1 & -1 & -1 & 2.35 & 2.33 \\
\hline 2 & 1 & -1 & -1 & 3.65 & 3.34 \\
\hline 3 & -1 & 1 & -1 & 2.63 & 2.52 \\
\hline
\end{tabular}




\begin{tabular}{|c|c|c|c|c|c|}
\hline 4 & 1 & 1 & -1 & 3.86 & 3.53 \\
\hline 5 & -1 & -1 & 1 & 2.83 & 2.78 \\
\hline 6 & 1 & -1 & 1 & 4.80 & 4.75 \\
\hline 7 & -1 & 1 & 1 & 3.10 & 3.03 \\
\hline 8 & 1 & 1 & 1 & 5.12 & 5.06 \\
\hline 9 & -1.682 & 0 & 0 & 2.11 & 2.09 \\
\hline 10 & 1.682 & 0 & 0 & 5.76 & 5.69 \\
\hline 11 & 0 & -1.682 & 0 & 2.98 & 2.98 \\
\hline 12 & 0 & 1.682 & 0 & 3.56 & 3.48 \\
\hline 13 & 0 & 0 & -1.682 & 2.32 & 2.15 \\
\hline 14 & 0 & 0 & 1.682 & 4.33 & 4.29 \\
\hline 15 & 0 & 0 & 0 & 3.35 & 3.27 \\
\hline 16 & 0 & 0 & 0 & 3.35 & 3.27 \\
\hline 17 & 0 & 0 & 0 & 3.35 & 3.27 \\
\hline 18 & 0 & 0 & 0 & 3.35 & 3.27 \\
\hline 19 & 0 & 0 & 0 & 3.35 & 3.27 \\
\hline 20 & 0 & 0 & 0 & 3.35 & 3.27 \\
\hline
\end{tabular}

\subsection{Development of mathematical model}

Coefficient of performance is function of Coil diameter, coil pitch and internal diameter of capillary and can be expressed as

$$
\mathrm{Y}=\mathrm{f}(\mathrm{D}, \mathrm{P}, \mathrm{d})
$$

Where $\mathrm{Y}$ is the theresponse, $\mathrm{D}$ is the Coil Diameter(mm),P is the Coil Pitch ( $\mathrm{mm})$, dis the inner coil diameter(mm)

For the three factors, the selected polynomial (regression) could be expressed as

$\mathrm{Y}=\mathrm{b}_{0}+\mathrm{b}_{1} \mathrm{D}+\mathrm{b}_{2} \mathrm{P}+\mathrm{b}_{3} d+\mathrm{b}_{11} \mathrm{D}^{2}+\mathrm{b}_{22} \mathrm{P}^{2}+\mathrm{b}_{33} \mathrm{~d}^{2}+\mathrm{b}_{12} \mathrm{DP}+$ $b_{13} \mathrm{Dd}+\mathrm{b}_{23} \mathrm{Pd}$

Where $\mathrm{B} 0$ is the free term of the regression equation, the coefficients b1, b2 and b3 is a linear term, the coefficients B11, B22, and b33, is a quadratic term, and the coefficient, b12, b13, and B23, is the interaction term. The coefficient values are calculated by regression analysis with the help of the following equation.

$$
\mathrm{b}_{0}=0.1663 \Sigma(\mathrm{Y})-0.0568 \Sigma \Sigma\left(\mathrm{X}_{\mathrm{ii}} \mathrm{Y}\right)
$$

$\mathrm{bj}=0.0732\left(\mathrm{X}_{\mathrm{i}} \mathrm{Y}\right)$

$\mathrm{b}_{\mathrm{ii}}=0.0625 \Sigma\left(\mathrm{X}_{\mathrm{ii}} \mathrm{Y}\right)+0.00689 \Sigma \Sigma\left(\mathrm{X}_{\mathrm{ii}} \mathrm{Y}\right)-0.0568$

$\mathrm{bij}=0.1250 \Sigma\left(\mathrm{X}_{\mathrm{ij}} \mathrm{Y}\right)$

EXPERT DESIGN 8.0.4 software package that is used to calculate the coefficient values fordifferent response and the results are presented in Table 3. The final mathematical model determined by the analysis above in the form of a code represented:

$\mathrm{COP}=3.27+0.88 \mathrm{D}+0.13 \mathrm{P}+0.55 \mathrm{~d}+0.01 \mathrm{DP}+0.25 \mathrm{Dd}$ $+0.02 \mathrm{Pd}+0.21 \mathrm{D}^{2}-0.02 \mathrm{P}^{2}-0.026 \mathrm{~d}^{2}(8)$

\subsection{Developed final mathematical model}

The developed final mathematical model equations in the coded form are given below: 

A REFRIGERATION SYSTEM WORKING WITH R404A

Table 3 Calculated regression coefficients of mathematical models

\begin{tabular}{|l|l|}
\hline Factor & Calculated coefficient of Performance \\
\hline Intercept & 3.2712 \\
\hline D & 0.8841 \\
\hline P & 0.1304 \\
\hline d & 0.5491 \\
\hline DP & 0.0075 \\
\hline Dd & 0.2475 \\
\hline Pd & 0.0225 \\
\hline$D^{2}$ & 0.2107 \\
\hline$P^{2}$ & -0.0225 \\
\hline$d^{2}$ & -0.0261 \\
\hline
\end{tabular}

\subsection{Checking the adequacy of the developed model}

The sufficiency of the version so grew then attempted the use of the techniques of studies of difference (ANOVA). ANOVA outcomes are given in table 4. Model F-esteem forty three.24implies which modelis outstanding.There truely zero. $01 \%$ possibility that the model F-truly really worth may take place due to clamor. The qualities "Prob> F" of under zero.0500 shows that a noteworthy model phrases. For this situation, D2, P2and d2are time period big models. Qualities more than 0.A thousand suggests that the term version isn't always big.

The coefficient of assurance esteem R2 offers a properly being goodness models. Values Thedetermined of reducing aspect fashions are displayed in desk 5. The estimation of $\mathrm{R} 2$ is constantly someplace within the style of 0 and 1 , and the worth demonstrates the precision of the version. For a first rate model, the estimation of R2 need to be close to 1 . In this model, determined R2 is zero.974946. This implies ninety seven. $4 \%$ of facts ofexperimental affirms similarity with thedata anticipated through the usage of the version in advance.

The balanced R2 estimation of zero.952398 too immoderate to be in any manner dutiful to ahigh model hugeness. R2of predicted 0.809642is in realistic concurrence with the balanced R2 of 0.952398. Measures sufficient exactness thesignal-to-clamor percentage. An huge share of 4 favored. In this research, the proportion changed into 22.21904, which indicates the sign anadequate. Disperse graph of an normal version is displayed in discern 1. The qualities of the watched and anticipated tendencies of the reactions were dispersed close to tothe forty five ${ }^{\circ}$ line, demonstrating an about best assault of observational fashions created.

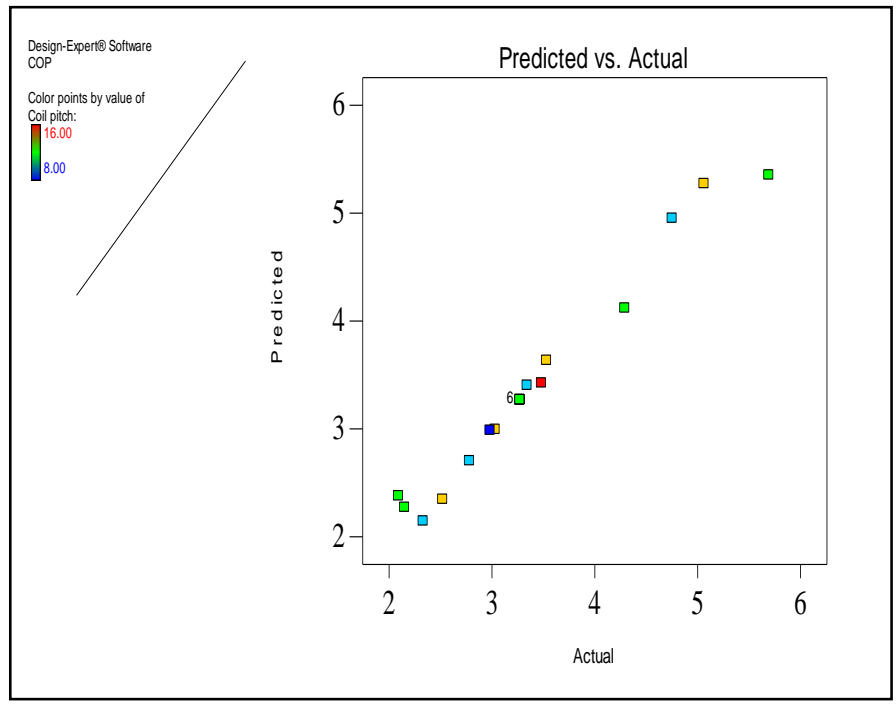

Fig.1 Predicted COP Vs Actual COP 
Table 4. ANOVA test results

\begin{tabular}{|l|c|c|c|c|c|c|}
\hline \multicolumn{7}{|l|}{ ANOVA test results } \\
\hline Source & $\begin{array}{c}\text { Sum of } \\
\text { squares }\end{array}$ & $\begin{array}{c}\text { Degree of } \\
\text { freedom }\end{array}$ & $\begin{array}{c}\text { Mean } \\
\text { square }\end{array}$ & F value & Prob>F & Result \\
\hline Model & 16.21503167 & 9 & 1.80167 & 43.23784 & $<0.0001$ & significant \\
\hline D & 10.67540455 & 1 & 10.6754 & 256.1964 & $<0.0001$ & \\
\hline P & 0.23223445 & 1 & 0.232234 & 5.573337 & 0.0399 & \\
\hline d & 4.11775287 & 1 & 4.117753 & 98.82093 & $<0.0001$ & \\
\hline D - P & 0.00045 & 1 & 0.00045 & 0.010799 & 0.9193 & \\
\hline D - d & 0.49005 & 1 & 0.49005 & 11.76059 & 0.0064 & \\
\hline P - d & 0.00405 & 1 & 0.00405 & 0.097195 & 0.7616 & \\
\hline$D^{2}$ & 0.640308934 & 1 & 0.640309 & 15.36662 & 0.0029 & \\
\hline$P^{2}$ & 0.007333684 & 1 & 0.007334 & 0.175999 & 0.6837 & \\
\hline$d^{2}$ & 0.009812606 & 1 & 0.009813 & 0.23549 & 0.6379 & \\
\hline Residual & 0.416688328 & 10 & 0.041669 & & & \\
\hline Lack of fit & 0.416688328 & 5 & 0.083338 & & & Not significant \\
\hline Pure error & 0 & 5 & 0 & & & \\
\hline Cor.total & 16.63172 & 19 & & & \\
\hline
\end{tabular}

Table 5 Coefficient of determination value

\begin{tabular}{|l|l|l|l|}
\hline $\mathrm{R}^{2}$ & Adjusted $\mathrm{R}^{2}$ & Predicted $\mathrm{R}^{2}$ & Adequate Precision \\
\hline 0.974946 & 0.952398 & 0.809642 & 22.21904 \\
\hline
\end{tabular}

\subsection{Confirmation experiments}

Trials have been directed to test the relapse condition (eight). Narrow tube curl distance during (D) inside the slim width (d) and the pitch of the slender cylinder $(\mathrm{P})$ differs, but it's far implemented inside the shape lattice. The results have been agreeable and the subtleties are delivered in table five.

\section{INVESTIGATION OF THE EFFECTS \& RESULTS}

The effect of diverse gadget parameters at the co-effective of execution using R404a refrigerant is evaluated from exploratory perceptions are added in Figures (2-4)

\section{1 impact of Coil size (D)}

Determine 2 shows the impact of the curl breadth outstanding cylinder at usual performance.It coefficient taken into consideration that to be the gap across of the loop builds the coefficient of execution moreover expanded. The bigger the breadth of the cylinder, the larger the surface location and consequently higher COP. Along those traces, for the loop measurement of extra than $300 \mathrm{~mm}$ variety in execution become to a tremendous extent left out.

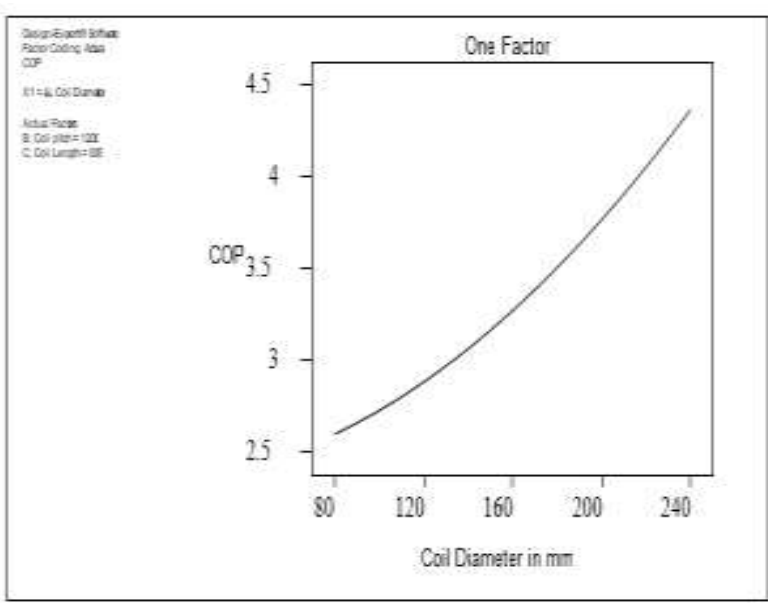

Fig.2 Coil diameter Vs Coefficient of performance

Published By: 


\subsection{Effect of coil pitch( $P$}

parent three indicates the effect of the sector loop at the coefficient of execution. attributable to a helical looped slender cylinder discipline effect on framework execution is less. a totally little rate at COP development skilled with extended pitch, the helical geometry of the narrow tube has a form like a directly hairlike cylinder.
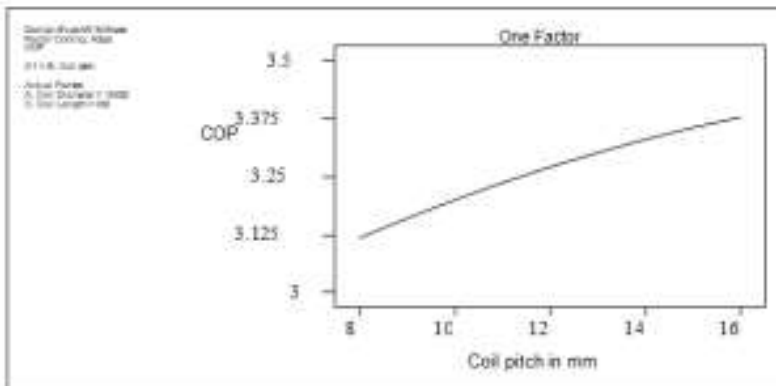

Fig 3.Coil pitch Vs Coefficient of performance

\subsection{Effect of inner diameter of thecoil $(d)$}

Parent 4 represents the immediately effect of the size of the loop in the hairlike to the coefficient of execution of the framework. It appears that evidently because the inner distance across of the loop increment the coefficient of execution of the framework moreover increments. As the space all through of the vessels builds refrigerant mass flow fee increment and no lessen and no decline in frictional opposition and henceforth multiplied COP.

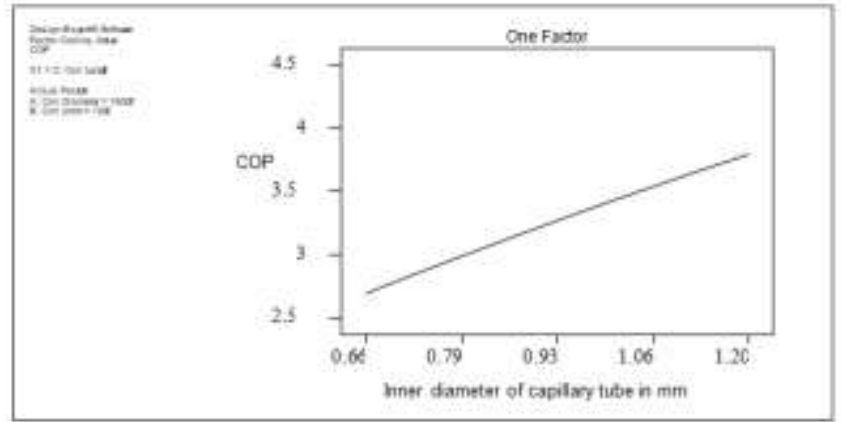

Fig 4.Inner diameter of capillary tube Vs coefficient of performance

\section{CONCLUSIONS}

The accompanying finishes of the examination landed on the top.

1. The relationship a number of the parameters of the system for R404a refrigerant has been set. Response floor technique embraced to build up a relapse model, were analyzed for his or her sufficiency making use of ANOVA check, expend outlines and noticed as proper.

2. Confirmation exams exhibit propelled fashions are very genuine.

Three. The growth in loop distance during, pitch and width inside the excellent increment the coefficient of execution of the framework.

\section{REFERENCES}

1. Kim S.G, Kim and Rao S.T, "Trial research of the exhibition of R-22, R-407C and R - 410a in a few hairlike cylinders for air - conditioner", InternationalJournal Refrigeration 25 (2002) 521-31.
2. C.Z Wei, Lin Y.T, Wang C.C, and Lev J.S, "An exploratory research of the exhibition of the hairlike cylinder for refrigerant R-407C", ASHRAE Trans, 27 (2001) 634-eight.

3. Akintunde, M.A, "test research of the exhibition of R-12 and R-134a within the first-rate cylinder for refrigeration frameworks", Nigeria J. Tech. Devel, 4 (2004) 1-12.

4. Akintunde M.A, "effect of the field in the slender cylinder looped fume pressure refrigeration framework execution ', AU magazine, eleven (1) (2007) 14-22.

5. Melo C, trial research of adiabatic slim cylinders, magazine of accomplished Thermal Engineering, 19 (6) (1999) 669-684. 